\title{
Preliminary verification for application of a support vector machine-based cloud detection method to GOSAT-2 CAI-2
}

\author{
Yu Oishi ${ }^{1, a}$, Haruma Ishida ${ }^{2}$, Takashi Y. Nakajima ${ }^{3}$, Ryosuke Nakamura $^{1}$, and Tsuneo Matsunaga ${ }^{4}$ \\ ${ }^{1}$ National Institute of Advanced Industrial Science and Technology, 2-4-7 Aomi, Koto, Tokyo 135-0064, Japan \\ ${ }^{2}$ Meteorological Research Institute, 1-1 Nagamine, Tsukuba, Ibaraki 305-0052, Japan \\ ${ }^{3}$ Research and Information Center, Tokai University, 2-28-4 Tomigaya, Shibuya, Tokyo 151-0063, Japan \\ ${ }^{4}$ National Institute for Environmental Studies, 16-2 Onogawa, Tsukuba, Ibaraki 305-8506, Japan \\ ${ }^{a}$ currently at: National Agriculture and Food Research Organization, 3-1-1 Kannondai, Tsukuba, Ibaraki 305-8517, Japan
}

Correspondence: Yu Oishi (oishi.yu@affrc.go.jp)

Received: 18 December 2017 - Discussion started: 22 January 2018

Revised: 25 April 2018 - Accepted: 29 April 2018 - Published: 17 May 2018

\begin{abstract}
The Greenhouse Gases Observing Satellite (GOSAT) was launched in 2009 to measure global atmospheric $\mathrm{CO}_{2}$ and $\mathrm{CH}_{4}$ concentrations. GOSAT is equipped with two sensors: the Thermal And Near infrared Sensor for carbon Observations (TANSO)-Fourier transform spectrometer (FTS) and TANSO-Cloud and Aerosol Imager (CAI). The presence of clouds in the instantaneous field of view of the FTS leads to incorrect estimates of the concentrations. Thus, the FTS data suspected to have cloud contamination must be identified by a CAI cloud discrimination algorithm and rejected. Conversely, overestimating clouds reduces the amount of FTS data that can be used to estimate greenhouse gas concentrations. This is a serious problem in tropical rainforest regions, such as the Amazon, where the amount of useable FTS data is small because of cloud cover. Preparations are continuing for the launch of the GOSAT-2 in fiscal year 2018. To improve the accuracy of the estimates of greenhouse gases concentrations, we need to refine the existing CAI cloud discrimination algorithm: Cloud and Aerosol Unbiased Decision Intellectual Algorithm (CLAUDIA1). A new cloud discrimination algorithm using a support vector machine (CLAUDIA3) was developed and presented in another paper. Although the use of visual inspection of clouds as a standard for judging is not practical for screening a full satellite data set, it has the advantage of allowing for locally optimized thresholds, while CLAUDIA1 and -3 use common global thresholds. Thus, the accuracy of visual inspection is better than that of these algorithms in most regions, with the exception of
\end{abstract}

snow- and ice-covered surfaces, where there is not enough spectral contrast to identify cloud. In other words, visual inspection results can be used as truth data for accuracy evaluation of CLAUDIA1 and -3 . For this reason visual inspection can be used for the truth metric for the cloud discrimination verification exercise. In this study, we compared CLAUDIA1-CAI and CLAUDIA3-CAI for various land cover types, and evaluated the accuracy of CLAUDIA3-CAI by comparing both CLAUDIA1-CAI and CLAUDIA3-CAI with visual inspection $(400 \times 400$ pixels $)$ of the same CAI images in tropical rainforests. Comparative results between CLAUDIA1-CAI and CLAUDIA3-CAI for various land cover types indicated that CLAUDIA3-CAI had a tendency to identify bright surface and optically thin clouds. However, CLAUDIA3-CAI had a tendency to misjudge the edges of clouds compared with CLAUDIA1-CAI. The accuracy of CLAUDIA3-CAI was approximately $89.5 \%$ in tropical rainforests, which is greater than that of CLAUDIA1-CAI $(85.9 \%)$ for the test cases presented here.

\section{Introduction}

The Greenhouse Gases Observing Satellite (GOSAT) was launched in 2009 to measure global atmospheric $\mathrm{CO}_{2}$ and $\mathrm{CH}_{4}$ concentrations. Preparations are continuing for the launch of its successor, GOSAT-2, in the fiscal year 2018. The mission objectives of GOSAT-2 are as follows: to continue and improve the satellite measurements of major green- 


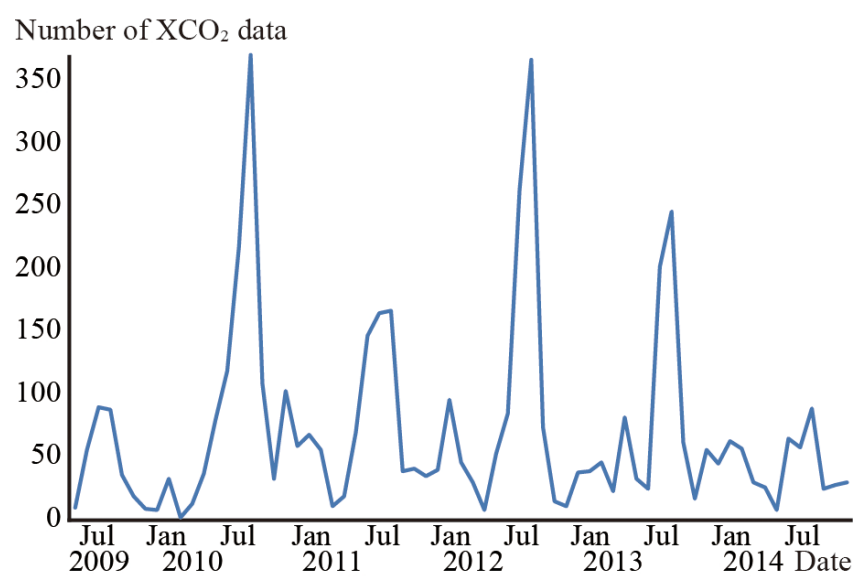

Figure 1. Monthly changes in the number of FTS L2 $\mathrm{XCO}_{2}$ data in the Amazon. The five-point cross-track scan mode was used until 1 August 2010, when it was replaced with the three-point crosstrack scan mode. Therefore the numbers themselves before and after 1 August 2010 cannot be compared.

house gases performed by GOSAT, to monitor the effects of climate change and human activities on the carbon cycle, and to contribute to climate science and climate change related policies (NIES GOSAT-2 Project, 2014). These policies include Reducing Emissions from Deforestation and Forest Degradation and the role of conservation; sustainable management of forests and enhancement of forest carbon stocks in developing countries (REDD+); and the Joint Crediting Mechanism (JCM), which was proposed by the Japanese government to facilitate the diffusion of leading low-carbon technologies, products, systems, services, and infrastructure in developing countries (Ministry of the Environment, Japan, 2015). Monthly regional $\mathrm{CO}_{2}$ fluxes are estimated from the column-averaged dry-air mole fractions of $\mathrm{CO}_{2}\left(\mathrm{XCO}_{2}\right)$ retrieved from spectral observations made by GOSAT (Maksyutov et al., 2013). The results are publicly available as the $\mathrm{L}_{4} \mathrm{~A} \mathrm{CO}_{2}$ product (Maksyutov et al., 2014). The expected role of the $\mathrm{CO}_{2}$ fluxes estimated from the GOSAT data is the system for measurement, reporting and verification (MRV) of $\mathrm{CO}_{2}$ fluxes estimated from forest inventory data. Currently, the uncertainty of the $\mathrm{L} 4 \mathrm{~A} \mathrm{CO}$ product is about $0.9 \mathrm{Gt}-\mathrm{C}$ region ${ }^{-1} \mathrm{yr}^{-1}$ in the Amazon (L4A $\mathrm{CO}_{2}$ product $\mathrm{V} 02.03$ in region $\ln 09-12,2009-2012$ ). Thus, the total net $\mathrm{CO}_{2}$ flux from deforestation for the period 2000 2010 in tropical America was estimated to be $0.56 \mathrm{Gt}_{-} \mathrm{C} \mathrm{yr}^{-1}$ (Baccini et al., 2012). It is required to reduce the uncertainty of the $\mathrm{L} 4 \mathrm{~A} \mathrm{CO}_{2}$ product by a factor of 16 , assuming that the MRV for REDD+ and JCM needs an accuracy of $10 \%$.

GOSAT is equipped with two sensors: the Thermal And Near infrared Sensor for carbon Observations (TANSO)Fourier transform spectrometer (FTS) and TANSO-Cloud and Aerosol Imager (CAI) (Table 1). The presence of clouds in the instantaneous field of view of the FTS leads to incor-
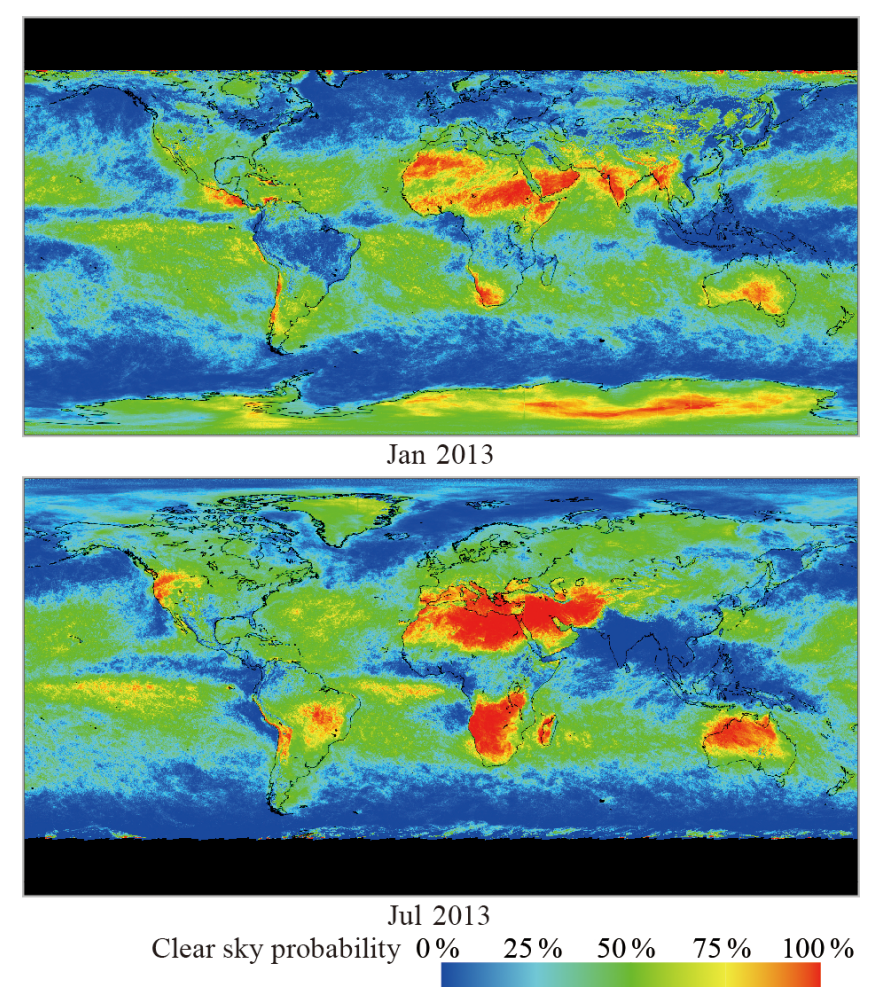

Figure 2. Clear-sky probability at $0.1^{\circ} \times 0.1^{\circ}$ calculated with MYD35_L2. There are low clear-sky probabilities over most tropical rainforests because the moisture helps to create clouds.

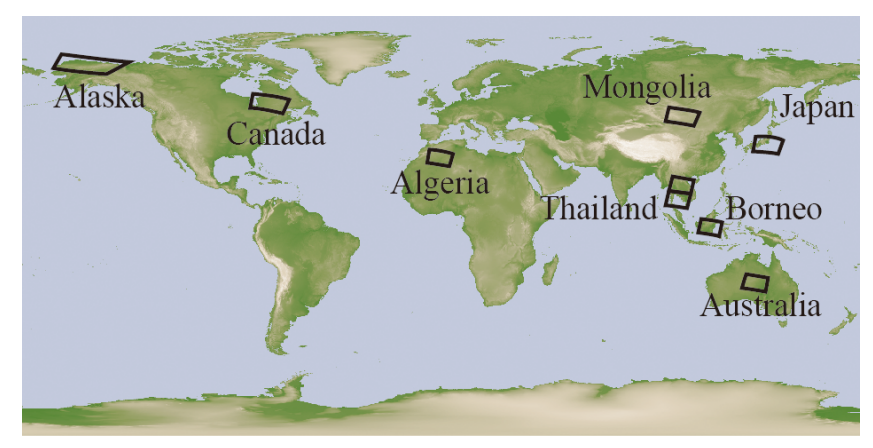

Figure 3. Study areas for various land cover types. Black rectangles indicate the locations of CAI frames.

rect estimates of greenhouse gas concentrations (Uchino et al., 2012). To solve this problem, the FTS data suspected to have cloud contamination must be identified by the Cloud and Aerosol Unbiased Decision Intellectual Algorithm used with CAI (CLAUDIA1-CAI) (Ishida and Nakajima, 2009) and rejected. The cloud information is publicly available as the CAI L2 cloud flag product. However, CAI does not have a thermal infrared band. In general, cirrus cloud is identified by using multiple thermal infrared bands, which include water vapor absorption bands (Ishida et al., 2011a). Meanwhile, the FTS has a $2 \mu \mathrm{m}$ band that contains many strong water vapor absorption bands. Moreover, the CAI L2 cloud flag prod- 
Table 1. Specifications of CAI.

\begin{tabular}{lrrrr}
\hline & Band 1 & Band 2 & Band 3 & Band 4 \\
\hline $\begin{array}{l}\text { Spectral coverage } \\
(\mu \mathrm{m})\end{array}$ & NUV & Red & NIR & SWIR \\
\hline $\begin{array}{l}\text { Swath }(\mathrm{km}) \\
0.370-0.390\end{array}$ & $0.664-0.684$ & $0.860-0.880$ & $1.56-1.65$ \\
\hline $\begin{array}{l}\text { Spatial resolution } \\
\text { At nadir }(\mathrm{m})\end{array}$ & 1000 & 1000 & 1000 & 750 \\
\hline
\end{tabular}

Table 2. GOSAT CAI L1B product and CAI L2 cloud flag product used for various land cover types in this study. Land cover was derived from the MODIS land cover type product (MCD12). Japan scenes include urban areas.

\begin{tabular}{lll}
\hline Location (CAI Path_Frame) & Data period & Land cover \\
\hline Australia (4_35) & 3 April 2012-3 March 2014 & Open shrublands \\
Japan (5_25) & 1 April 2012-1 March 2014 & Mixed forests \\
Borneo (7_31) & 3 April 2012-3 March 2014 & Evergreen broadleaf forest \\
Thailand 1 (9_28) & 2 April 2012-2 March 2014 & Cropland/natural vegetation \\
Thailand 2 (9_29) & 2 April 2012-2 March 2014 & Cropland/natural vegetation \\
Mongolia (10_23) & 3 April 2012-3 March 2014 & Grasslands \\
Algeria (22_26) & 3 April 2012-3 March 2014 & Barren or sparsely vegetated \\
Canada (32_22) & 1 April 2012-1 March 2014 & Evergreen needleleaf forest \\
Alaska (43_19) & 1 April 2012-1 March 2014 & Open shrublands \\
\hline
\end{tabular}

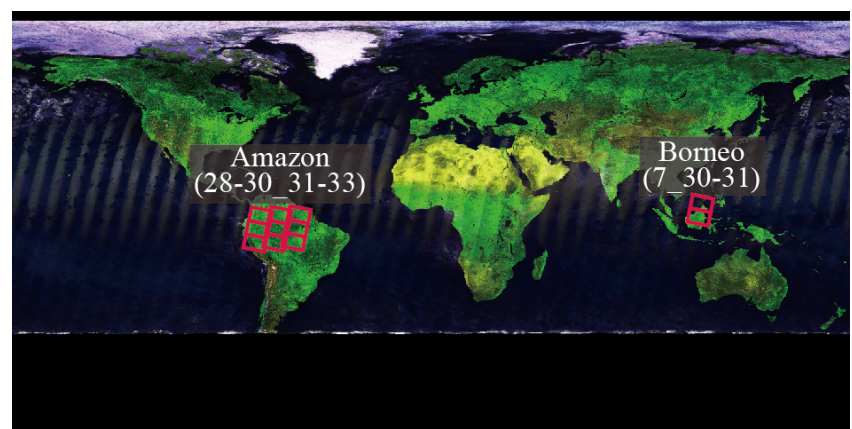

Figure 4. Study areas in Borneo and the Amazon. CAI path and frame system: XX_YY (XX indicates CAI path number and YY indicates CAI frame number). Red rectangles indicate the locations of CAI frames. The background image was generated from the CAI L3 global reflectance distribution product (15 June to 14 July 2013).

uct may not be sensitive enough to detect clouds of subpixel size in ocean observations. To cope with these difficulties, the FTS data suspected to have cloud contamination are identified by two additional tests: the $2 \mu \mathrm{m}$ band test and the CAI coherent test (Yoshida et al., 2010). Conversely, overestimation of clouds reduces the amount of the FTS data that can be used to estimate greenhouse gas concentrations. This is a serious problem in tropical rainforest regions, such as the Amazon, where there is a small amount of suitable FTS data (approximately $3 \%$ of the number of observations) because of cloud cover (Figs. 1 and 2). For this reason we need to optimize thresholds between cloudy and clear sky because there are tradeoffs in maximizing cloud detection accuracy while minimizing false detection. To solve the problem, a new cloud discrimination algorithm (CLAUDIA3) using a support vector machine (SVM) (Vapnik and Lerner, 1963) was developed (Ishida et al., 2018). CLAUDIA3 can automatically identify the optimized thresholds using clear-sky training data, although CLAUDIA1 requires setting various thresholds by radiative transfer calculation results and fine tuning in some methods. Verification was also performed by comparing it with the MODIS cloud mask algorithm (Ackerman et al., 2010) and ceilometer data provided by the Atmospheric Radiation Measurement Climate Research Facility (Mather and Voyles, 2013) in Ishida et al. (2018). Furthermore the impact of different support vector generation procedures on cloud discrimination using CLAUDIA3 has also been evaluated in a previous study (Oishi et al., 2017).

The accuracy of CLAUDIA1-CAI was evaluated by comparing it with the MODIS/Aqua cloud mask data product (MYD35) (Ackerman et al., 2010) because the MODIS cloud mask algorithm uses a larger number of bands for cloud discrimination than CLAUDIA1-CAI, and CLAUDIA1 was developed based on the MODIS cloud mask algorithm (Taylor et al., 2012; Ishida et al, 2011b). However, these comparisons cannot identify common weak points in the algorithms and another verification method is required. Although the use of visual inspection of clouds as a standard is not practical for screening a full satellite data set, it has the advantage of allowing for locally optimized thresholds, while 
Table 3. GOSAT CAI L1B product and CAI L2 cloud flag product used for rainforests in this study.

\begin{tabular}{lr|rr}
\hline & Borneo & \multicolumn{2}{|c}{ Amazon } \\
\hline $\begin{array}{l}\text { Date } \\
(\mathrm{yy} / \mathrm{mm} / \mathrm{dd})\end{array}$ & $\begin{array}{r}\text { Location } \\
\text { (CAI Path_Frame) }\end{array}$ & $\begin{array}{r}\text { Date } \\
(\mathrm{yy} / \mathrm{mm} / \mathrm{dd})\end{array}$ & $\begin{array}{r}\text { Location } \\
\text { (CAI Path_Frame) }\end{array}$ \\
\hline $10 / 04 / 02$ & $7 \_30$ & $11 / 08 / 28$ & $28 \_31$ \\
$10 / 01 / 02$ & $7 \_31$ & $11 / 08 / 28$ & $28 \_32$ \\
$10 / 04 / 02$ & $7 \_31$ & $11 / 08 / 28$ & $28 \_33$ \\
$10 / 07 / 01$ & $7 \_31$ & $11 / 08 / 29$ & $29 \_31$ \\
$10 / 07 / 07$ & $7 \_31$ & $10 / 08 / 28$ & $29 \_32$ \\
$10 / 07 / 13$ & $7 \_31$ & $11 / 02 / 03$ & $29 \_32$ \\
$10 / 07 / 19$ & $7 \_31$ & $11 / 04 / 01$ & $29 \_32$ \\
$10 / 07 / 28$ & $7 \_31$ & $11 / 06 / 03$ & $29 \_32$ \\
$10 / 09 / 02$ & $7 \_31$ & $11 / 08 / 02$ & $29 \_32$ \\
$10 / 11 / 01$ & $7 \_31$ & $11 / 08 / 08$ & $29 \_32$ \\
& & $11 / 08 / 14$ & $29 \_32$ \\
& & $11 / 08 / 23$ & $29 \_32$ \\
& & $11 / 08 / 29$ & $29 \_32$ \\
& & $11 / 10 / 01$ & $29 \_32$ \\
& & $11 / 12 / 03$ & $29 \_32$ \\
& & $11 / 08 / 29$ & $29 \_33$ \\
& & $11 / 08 / 30$ & $30 \_31$ \\
& & $11 / 08 / 30$ & $30 \_32$ \\
& & $11 / 08 / 30$ & $30 \_33$ \\
\hline
\end{tabular}

CLAUDIA 1 and -3 use common global thresholds. Thus, the accuracy of visual inspection is better than that of these algorithms in most regions, with the exception of snow- and icecovered surfaces, where there is not enough spectral contrast to distinguish cloud. In other words, visual inspection results can be used as truth data for accuracy evaluation of CLAUDIA1 and -3. For this reason visual inspection can be used as the truth metric for the verification exercise. Therefore, the accuracy of CLAUDIA1-CAI has also been evaluated by visual inspection in tropical rainforests (Oishi et al., 2014). In this study, we deal with the application of the CLAUDIA3 to GOSAT CAI data. Then, we compare CLAUDIA1-CAI and CLAUDIA3-CAI for various land cover types and evaluate their accuracy by comparing both against visual inspection $(400 \times 400$ pixels) of the same CAI images in tropical rainforests.

\section{Materials and methods}

\subsection{Study area and data}

The study area for directly comparing CLAUDIA1-CAI and CLAUDIA3-CAI for various land cover types is the same as in the previous study (Oishi et al., 2017) (Fig. 3) and the accuracy can be evaluated by comparing them against visual inspection in Borneo and the Amazon (Fig. 4).

The total forest area in the Amazon, Congo, and south-east Asia rainforest basins is over 13 million $\mathrm{km}^{2}$, which corresponds to one-third of the total global forest area (FAO and

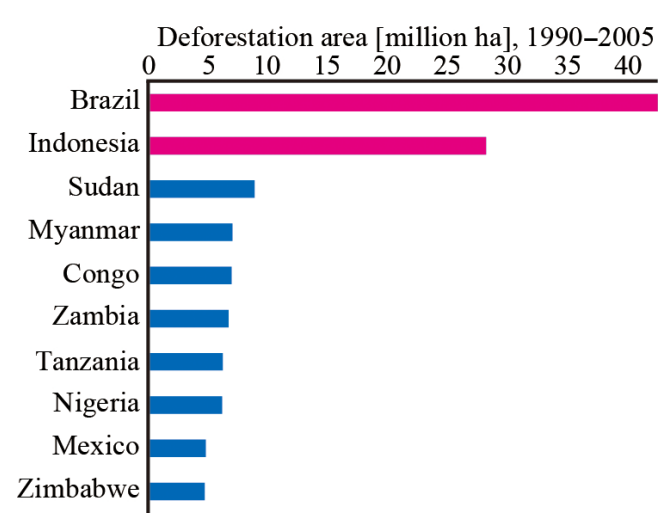

Figure 5. List of the top 10 countries for changes in deforestation area (million ha) from 1990 to 2005 . These were calculated with data from the Global Forest Resources Assessment 2005 (FAO, 2005).

ITTO, 2011). The three most forest-rich countries (Brazil, Democratic Republic of Congo, and Indonesia) account for $57 \%$ of the total global forest area (FAO and ITTO, 2011). However, the total net emissions of carbon from tropical deforestation and land use were estimated to be $1.0 \mathrm{Pg}_{-} \mathrm{C} \mathrm{yr}^{-1}$ in the three rainforest basins (Baccini et al., 2012). In particular, Brazil and Indonesia have by far the highest and second highest deforestation rates, respectively (Fig. 5). Therefore, the study areas for rainforests are Borneo and the Amazon (Fig. 4). 


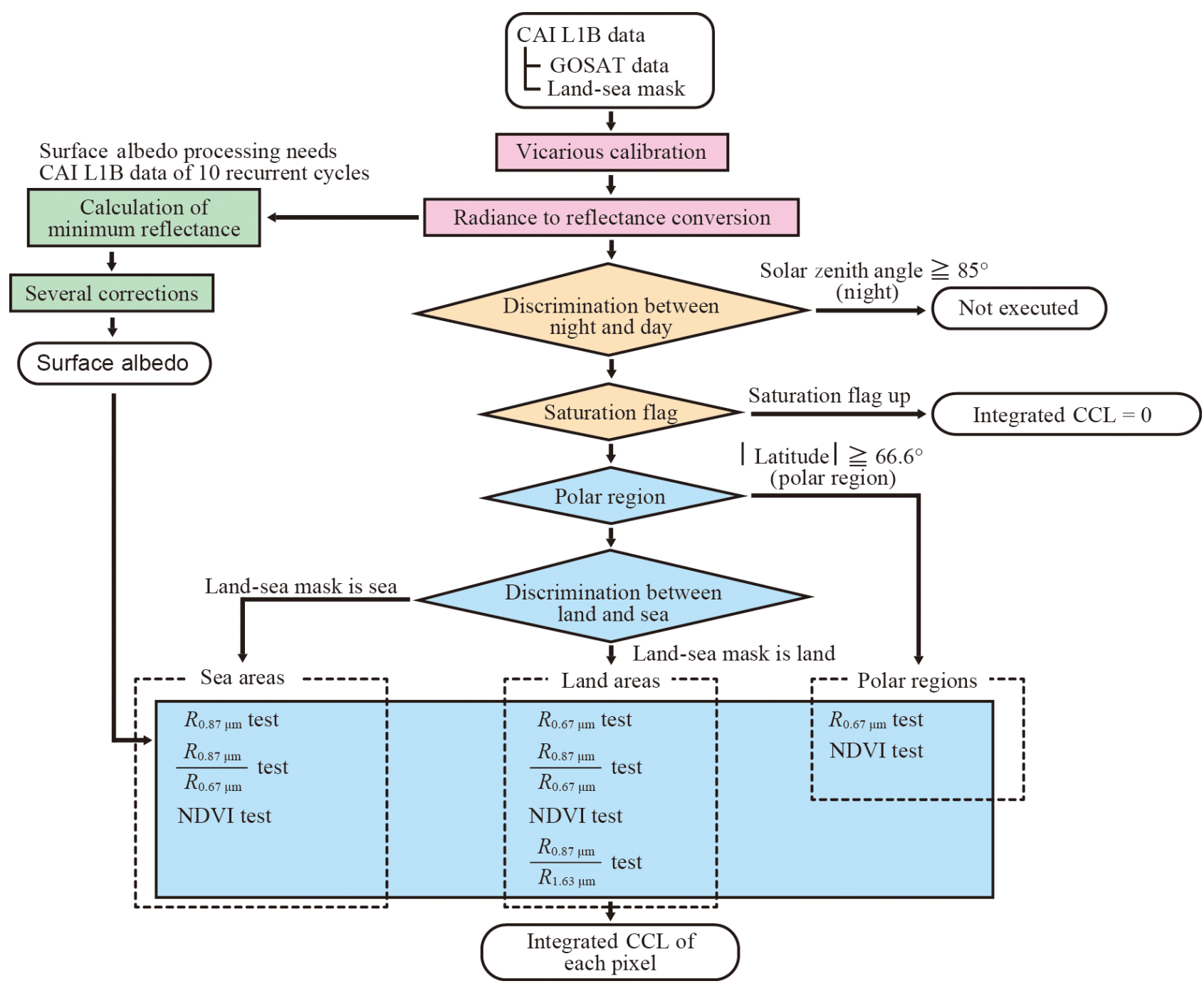

Figure 6. Flow chart for CLAUDIA1-CAI. For sun-glint areas, the thresholds are further increased based on the $R_{0.87 \mu m}$ test. CCL is confidence level, $R_{\text {wavelength }}$ is reflectance, NDVI is normalized difference vegetation index.

GOSAT returns to a similar footprint after 44 orbits $(44$ CAI paths) in 3 days. The satellite ground path of one orbit is divided into 60 equidistant CAI frames. We used the GOSAT CAI L1B product, which general users could download from the GOSAT User Interface Gateway (GUIG, https: //data.gosat.nies.go.jp), for various land cover types at the beginning of the month from 2012 to 2014 as was done in the previous study (Oishi et al., 2017) (Table 2), and for rainforests (Table 3). Recently the GUIG has been changed to GOSAT Data Archive Service (GDAS, https://data2.gosat. nies.go.jp/index_en.html). The spatial resolution of these products (pixel size at nadir) is $500 \mathrm{~m}$, and the image size is $2048 \times 1355$ pixels (approximately $1000 \times 680 \mathrm{~km}$ ). The CLAUDIA algorithm requires a land-sea mask and surface albedo data. The CAI L1B product includes a land-sea mask with $500 \mathrm{~m}$ resolution, which is generated from the Shuttle Radar Topography Mission's 15? land-sea mask and the
USGS Global Land 1-km AVHRR Data Set Project mask for areas at latitudes higher than $\pm 60^{\circ}$. Surface albedo data at $1 / 30^{\circ}$ resolution was generated from the CAI L1B data from 10 recurrent cycles by separating the land and water regions. This processing consists of three steps (Ishihara and Nobuta, 2013):

1. calculate the minimum reflectance to remove cloudcontaminated pixels,

2. cloud shadow correction (Fukuda et al., 2013), and

3. atmospheric correction.

\subsection{CLAUDIA1}

CLAUDIA1-CAI calculates the clear-sky confidence levels (CCL) for every threshold test and their comprehensive 


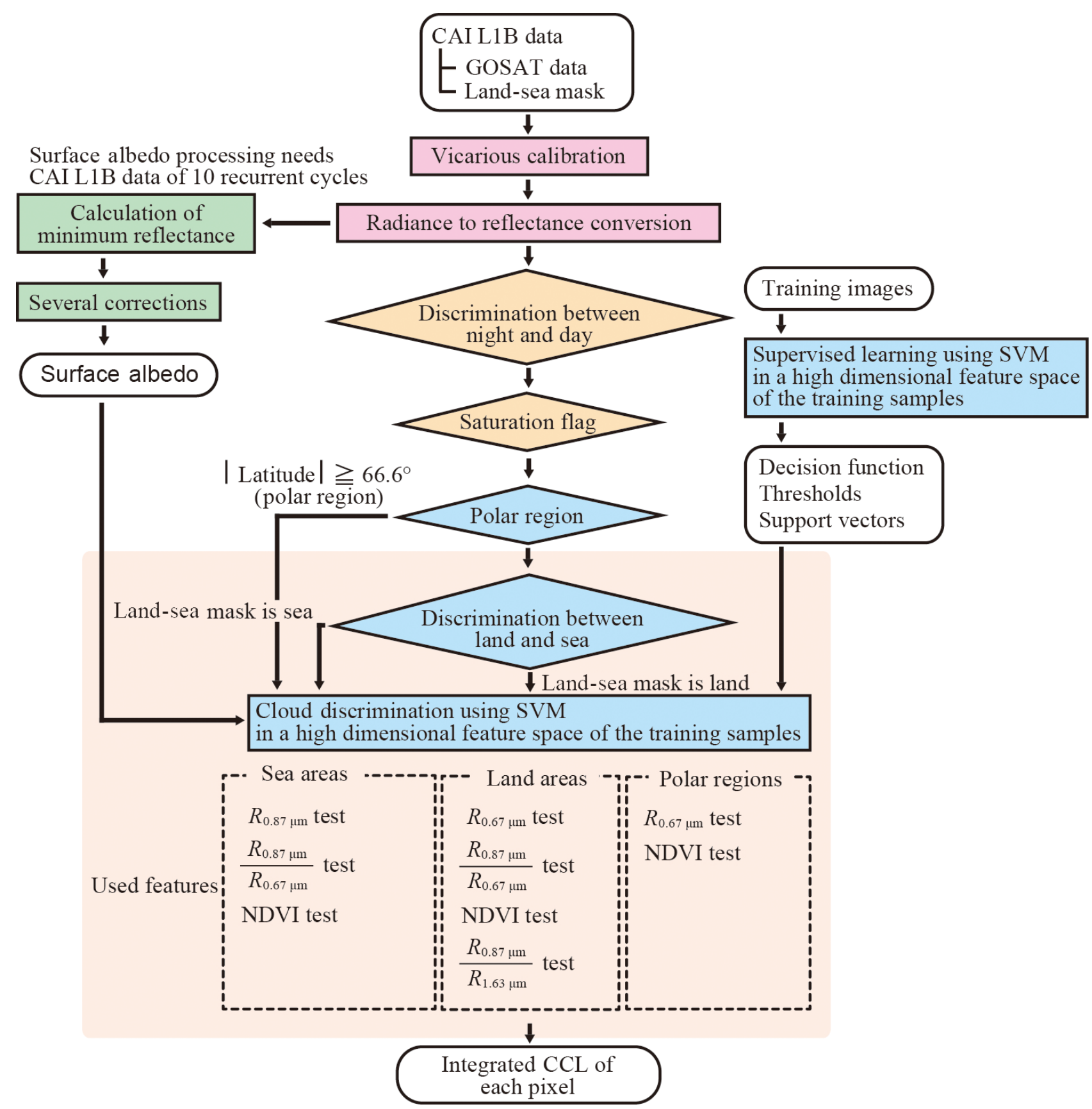

Figure 7. Flow chart for CLAUDIA3-CAI. CCL is clear-sky confidence level, Rwavelength is reflectance, NDVI is normalized difference vegetation index.

integration (Ishida and Nakajima, 2009). Integrated CCL of 0 means that the pixel is cloudy and 1 means that the pixel is cloud-free. Ambiguous pixels between cloudy and cloud-free are described by numerical values from 0 to 1 . The threshold below which the integrated CCL counts the pixel as cloudfree for GOSAT FTS L2 is 0.33 , otherwise the pixel is regarded as cloudy (Yoshida et al., 2010). The flow of the algorithm is shown in Fig. 6.

\subsection{New cloud discrimination algorithm (CLAUDIA3)}

CLAUDIA1 performs cloud discrimination by using thresholds set based on experience. The new cloud discrimination algorithm (CLAUDIA3, Ishida et al., 2018) applies SVM for objective threshold decision by using multivariate analysis. SVM is a supervised pattern recognition method. First, it determines the following items using training samples of typical clear and cloudy pixels: (1) a decision function to 


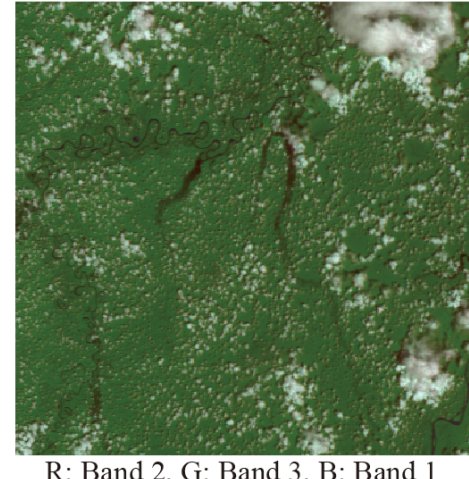

(a)

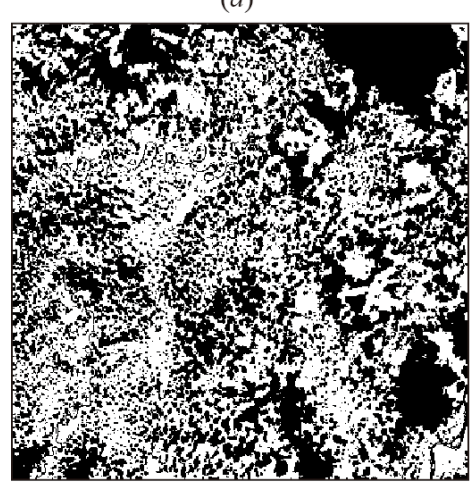

(c)

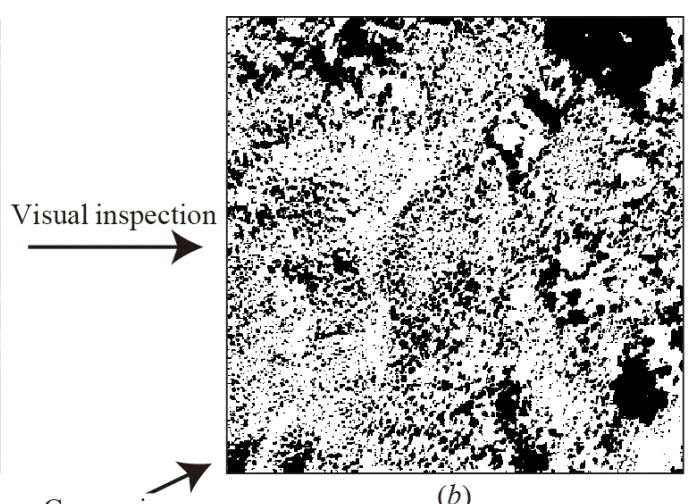

(b)

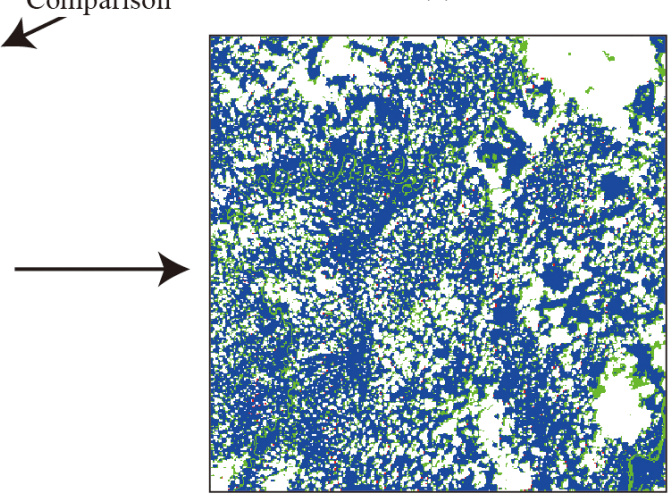

Both determined cloudy Determined as cloudy despite clear

Both determined clear

(d)

Figure 8. Analysis procedure. (a) CAI L1B image. (b) Visual inspection mask of CAI L1B. (c) Output mask from CLAUDIA1-CAI (CAI L2 cloud flag product) or CLAUDIA3-CAI. Pixels that are determined as cloudy are black. (d) Comparison of the visual inspection image and the output image. Pixels that are determined as cloudy in both are white. Pixels that are determined as clear in both are blue. Pixels that are determined as cloudy in the output image and clear in the visual inspection image are green. Unusual pixels that are determined as clear in the output image and cloudy in the visual inspection image are red.

Table 4. Yearly average accuracy, overlook, and overestimate for various land cover types.

\begin{tabular}{lrrrrrrrr}
\hline & Australia & Japan & Borneo & Thailand & Mongolia & Algeria & Canada & Alaska \\
\hline Accuracy (\%) & 96.4 & 94.3 & 79.4 & 88.7 & 89.0 & 96.6 & 92.1 & 84.2 \\
Overlook (\%) & 33.1 & 1.6 & 1.0 & 4.8 & 17.7 & 55.2 & 2.9 & 11.9 \\
Overestimate (\%) & 0.1 & 13.7 & 39.2 & 20.9 & 11.7 & 0.7 & 51.8 & 50.3 \\
\hline
\end{tabular}

discriminate between two classifications (clear and cloudy), (2) the thresholds, and (3) the support vectors, which are training samples specified by the decision function. The support vectors are decided in a high-dimensional feature space of the training samples. Next, it performs cloud discrimination by using the decision function, thresholds, and support vectors it determined. CLAUDIA3 applies the kernel trick (Boser et al., 1992) for soft-margin SVM (Cortes and Vapnik, 1995). The kernel uses a second-order polynomial (Eq. 1).

$K\left(\boldsymbol{x}_{i}, \boldsymbol{x}\right)=\frac{\left(\boldsymbol{x}_{i} \cdot \boldsymbol{x}+1\right)^{2}}{2}$ where $K$ is the kernel function, $\boldsymbol{x}_{i}$ is the support vector, and $\boldsymbol{x}$ is input data. The flow of CLAUDIA3-CAI is explained in Fig. 7. For CLAUDIA3-CAI, an integrated CCL of 0.5 corresponds to the separating hyperplane of clear support vectors and cloudy support vectors. In this study, we used two kinds of support vector: (1) support vectors generated by using MODIS data in February for cloud discrimination between November and April, and (2) support vectors generated by using MODIS data in August for cloud discrimination between May and October based on a previous study (Oishi et al., 2017). 

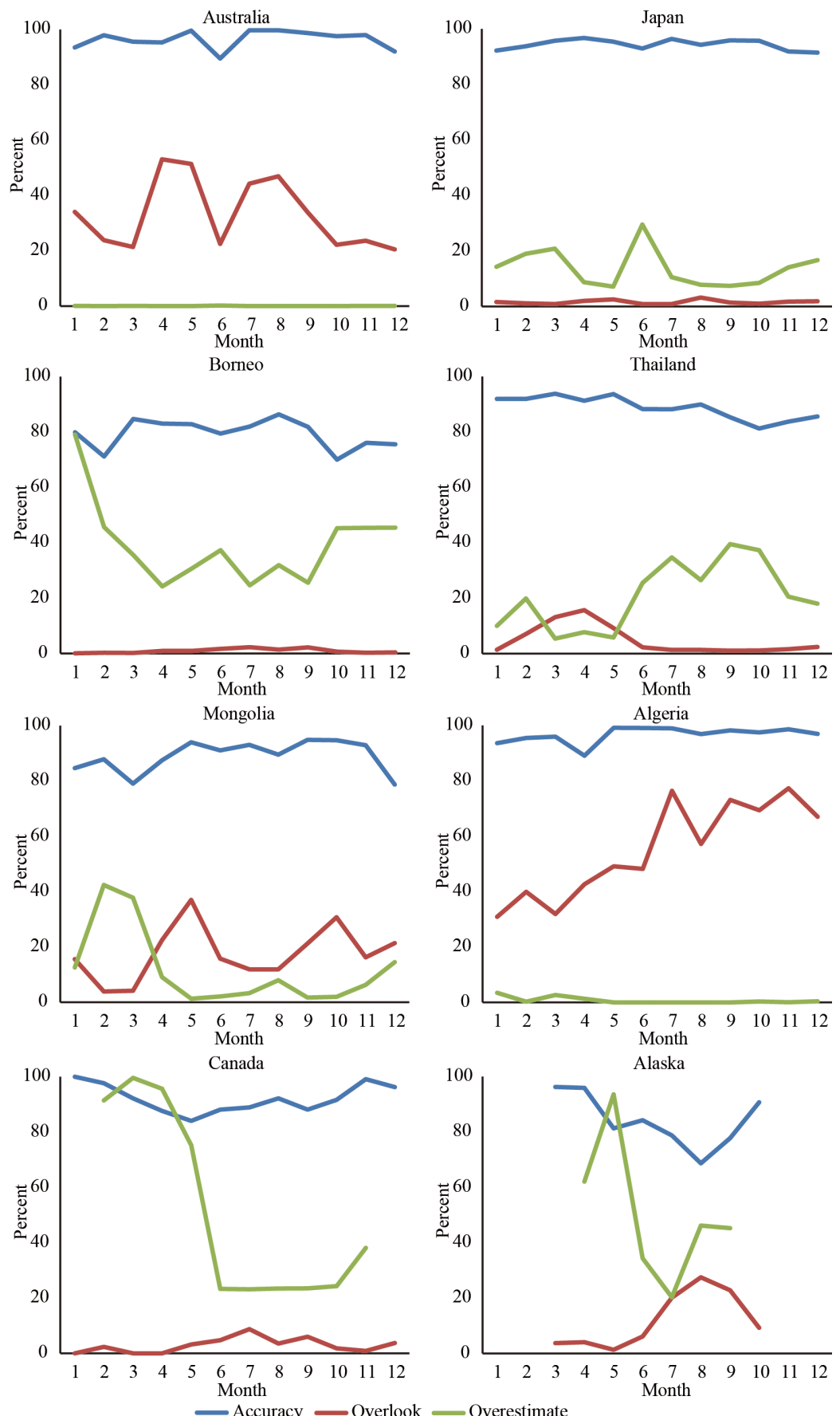

Figure 9. Monthly average accuracy, overlook, and overestimate for various land cover types. Blue line indicates accuracy, red line indicates overlook, and green line indicates overestimate.

\subsection{Analysis procedure for rainforests}

The analysis procedure consists of the following steps (Fig. 8).

1. Cut $400 \times 400$ pixels around the center of CAI L1B images.
2. Perform a visual inspection of the pixels cut from the CAI L1B images.

We performed a visual inspection of the presence or $a b-$ sence of clouds in every pixel $(400 \times 400$ pixels $)$.

3. Perform cloud discrimination by using CLAUDIA1CAI and CLAUDIA3-CAI. 

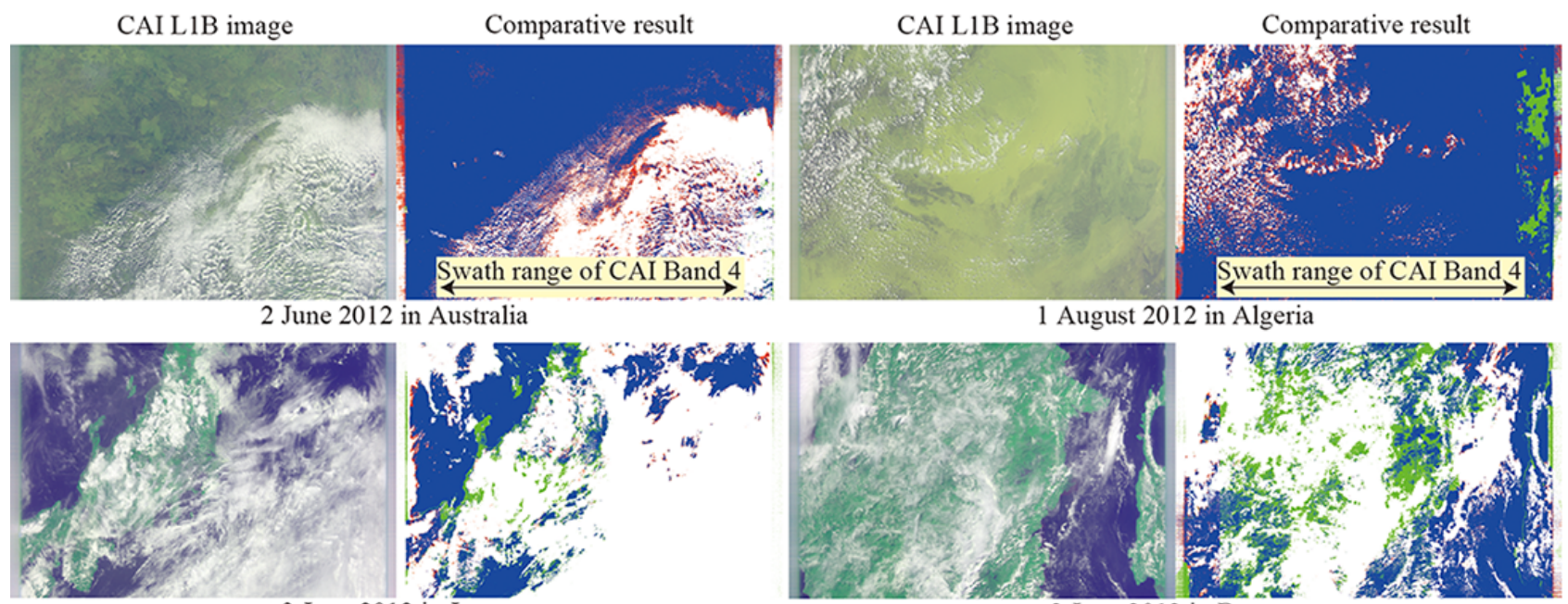

3 June 2012 in Japan

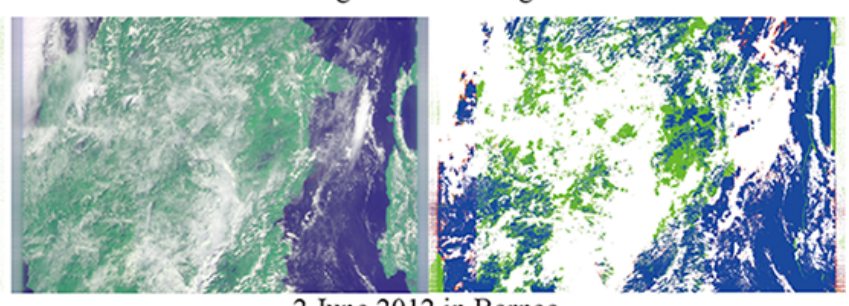

2 June 2012 in Borneo

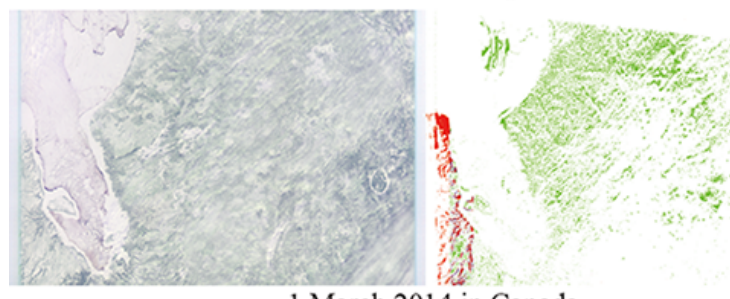

1 March 2014 in Canada

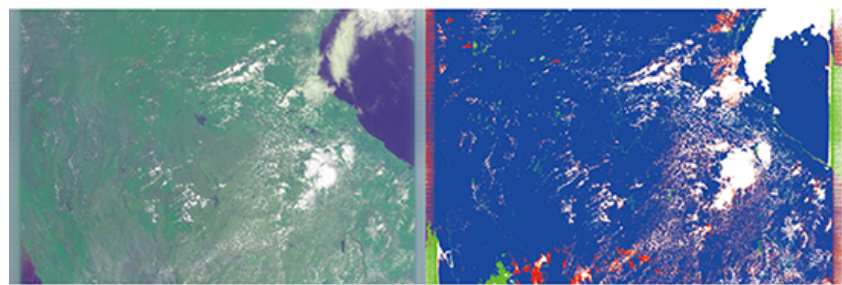

3 April 2013 in Thailand

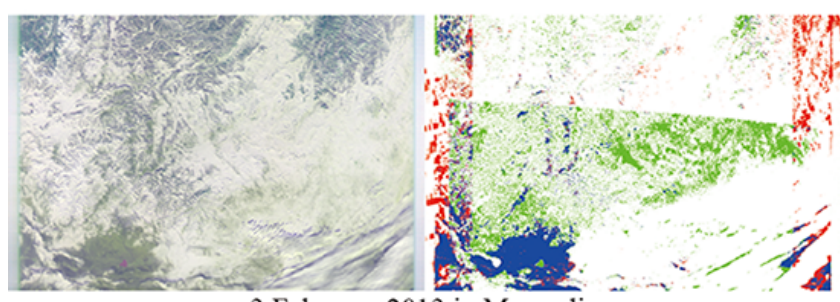

3 February 2013 in Mongolia

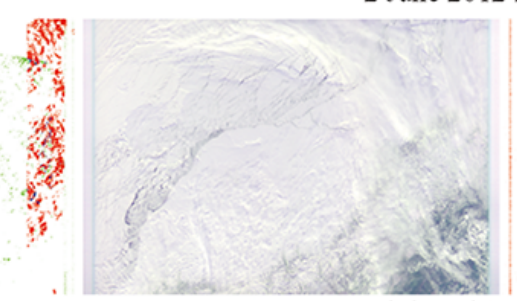

1 May 2012 in Alaska
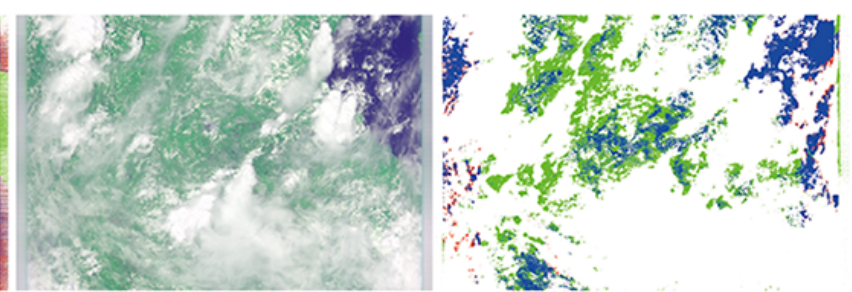

2 September 2012 in Thailand

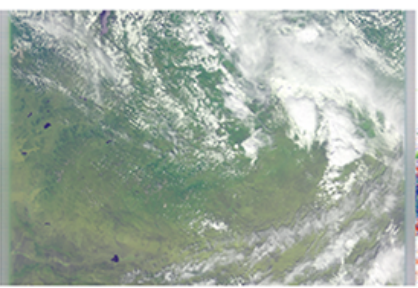

2 June 2012 in Mongolia

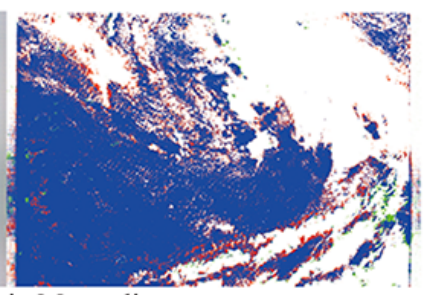

$\square$ Both determined cloudy $\square$ Overestimate (CLAUDIA3-CAI judged cloudy, despite CLAUDIA1-CAI judged clear)

Both determined clear $\square$ Overlook (CLAUDIA3-CAI judged clear, despite CLAUDIA1-CAI judged cloudy)

Figure 10. CAI L1B images (R: Band 2, G: Band 3, B: Band 1) and comparative results of CLAUDIA1-CAI and CLAUDIA3-CAI for various land cover types.

For CLAUDIA1-CAI, we produced output images setting the integrated-CCL threshold to 0.33. For CLAUDIA3-CAI, we produced output images setting the integrated-CCL threshold to 0.5 .

\section{Compare output with visual inspection.}

We colored the images by comparing the visual inspection images with the output images pixel by pixel.

\section{Results}

In this study, "accuracy" is defined as the ratio of the number of pixels for which the standard image and output from the cloud discrimination algorithm agree with the total number of pixels in the input image. "Overlook" is defined as the ratio of the number of pixels judged clear in the output and cloudy in the standard image to the number of pixels that 

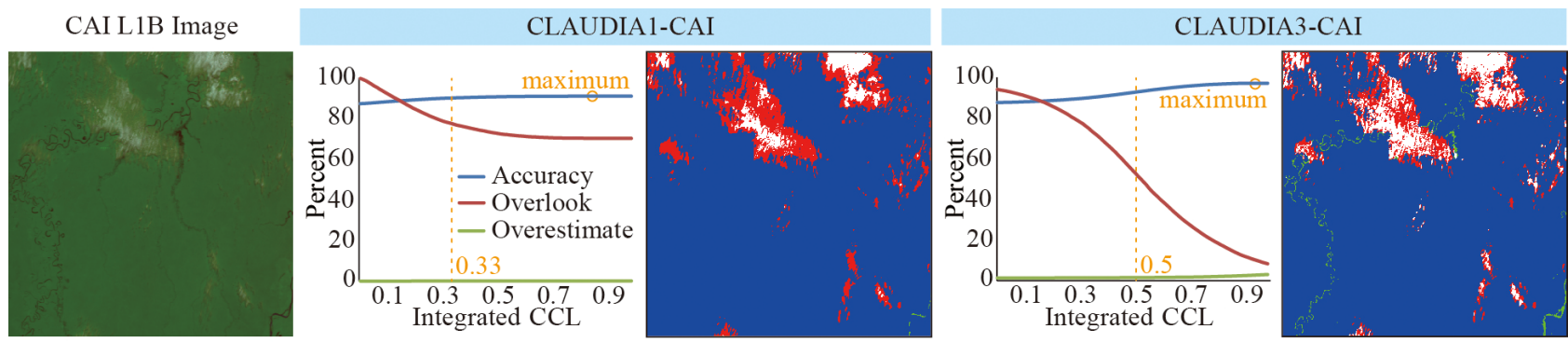

23 August 2011 in CAI Path 29, Frame 32 Low cloud cover (13\%)
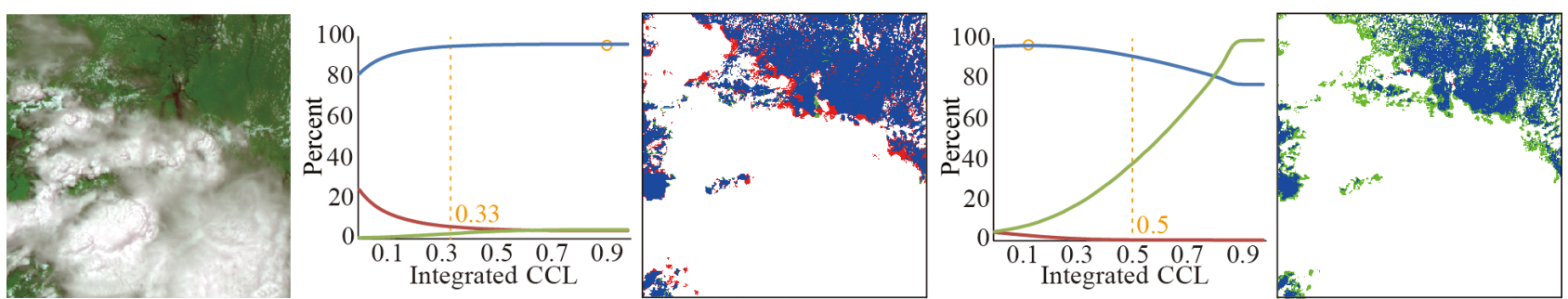

1 April 2011 in CAI Path 29, Frame 32

High cloud cover (75\%)
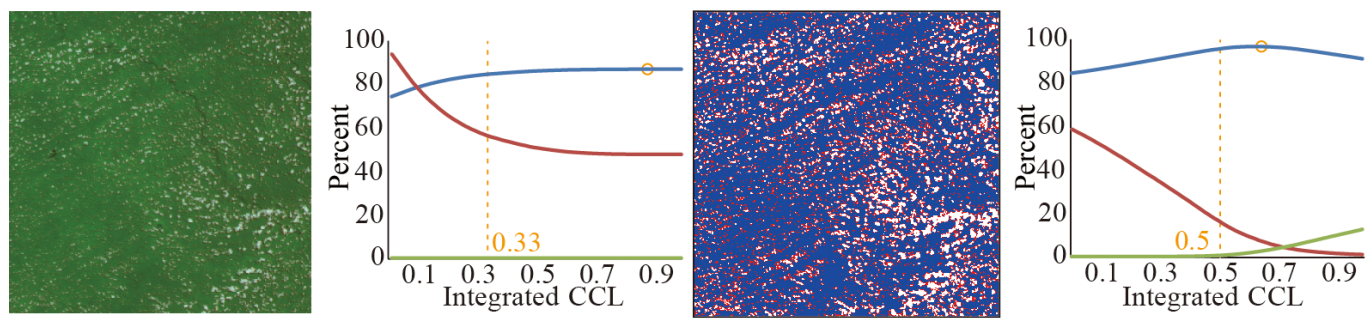

28 August 2011 in CAI Path 28, Frame 31 Small scattered clouds (27 \%)
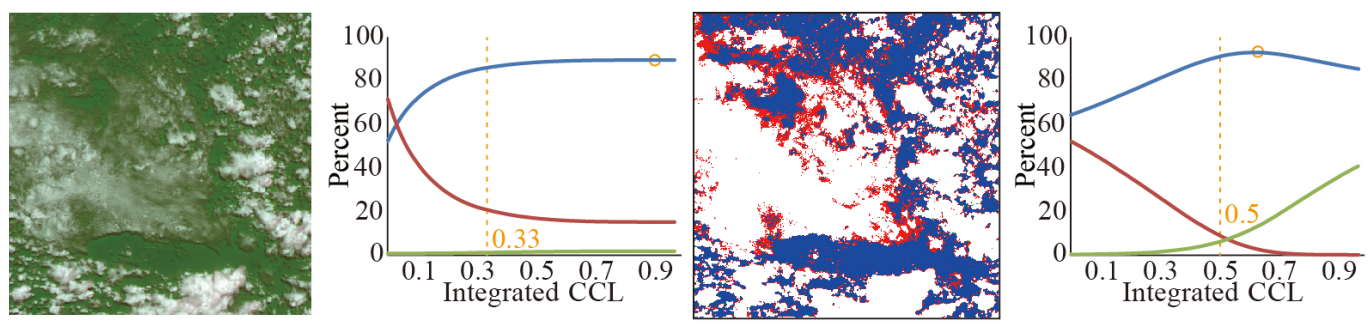

30 August 2011 in CAI Path 30, Frame 32 Optically thin clouds (67\%)

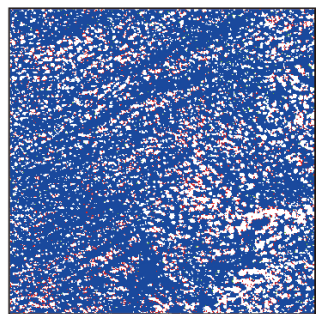

$\begin{array}{ll}\square \text { Both determined cloudy } & \text { Determined as cloudy despite clear } \\ \text { Both determined clear } & \text { Determined as clear despite cloudy }\end{array}$

Figure 11. Comparison of the visual inspection images and the output images in the Amazon. Orange circles indicate the maximum accuracy values. Orange dotted lines indicate the integrated-CCL thresholds. Blue line indicates the accuracy, red line indicates the overlook, and green line indicates the overestimate.

were judged cloudy in the standard image. "Overestimate" is defined as the ratio of the number of pixels judged cloudy in the output and clear in the standard image to the number of pixels judged clear in the standard image. These definitions are written as follows.

Accuracy $=\frac{\text { Both cloudy }+ \text { Both clear }}{\text { Total number of pixels }}$,
Overlook $=\frac{\text { Clear despite cloudy }}{\text { Both cloudy }+ \text { clear despite cloudy }}$,

Overestimate $=\frac{\text { Cloudy despite clear }}{\text { Both clear }+ \text { cloudy despite clear }}$.

\subsection{Results for various land cover types}

Figure 9 shows the monthly average accuracy, overlook, and overestimate for an integrated-CCL threshold of 0.33 for CLAUDIA1-CAI and 0.5 for CLAUDIA3-CAI; and Table 4 shows the yearly average accuracy, overlook, and overesti- 
Table 5. Results for integrated-CCL thresholds of 0.33 for CLAUDIA1-CAI and 0.5 for CLAUDIA3-CAI in the Amazon.

\begin{tabular}{|c|c|c|c|c|c|c|c|}
\hline \multirow[b]{2}{*}{$\begin{array}{l}\text { Date } \\
(\mathrm{yy} / \mathrm{mm} / \mathrm{dd})\end{array}$} & \multirow[b]{2}{*}{$\begin{array}{r}\text { Location } \\
(\text { CAI Path_Frame })\end{array}$} & \multicolumn{2}{|c|}{ Accuracy (\%) } & \multicolumn{2}{|c|}{ Overlook (\%) } & \multicolumn{2}{|c|}{ Overestimate (\%) } \\
\hline & & $\begin{array}{r}\text { CLAUDIA1 } \\
(0.33)\end{array}$ & $\begin{array}{r}\text { CLAUDIA3 } \\
(0.5)\end{array}$ & $\begin{array}{r}\text { CLAUDIA1 } \\
(0.33)\end{array}$ & $\begin{array}{r}\text { CLAUDIA3 } \\
(0.5)\end{array}$ & $\begin{array}{r}\text { CLAUDIA1 } \\
(0.33)\end{array}$ & $\begin{array}{r}\text { CLAUDIA3 (0.5) } \\
(0.5)\end{array}$ \\
\hline $11 / 08 / 28$ & 28_31 & 84.6 & 95.1 & 56.6 & 16.9 & 0.0 & 0.5 \\
\hline $11 / 08 / 28$ & 28_32 & 80.6 & 92.9 & 49.7 & 7.5 & 0.1 & 6.9 \\
\hline $11 / 08 / 28$ & 28_33 & 92.0 & 95.9 & 11.6 & 13.4 & 7.4 & 2.4 \\
\hline $11 / 08 / 29$ & 29_31 & 87.6 & 93.8 & 27.2 & 9.5 & 0.3 & 3.5 \\
\hline $10 / 08 / 28$ & $29 \_32$ & 89.8 & 90.8 & 32.6 & 9.9 & 1.7 & 9.0 \\
\hline $11 / 02 / 03$ & $29 \_32$ & 86.6 & 92.9 & 35.5 & 2.4 & 0.5 & 9.9 \\
\hline $11 / 04 / 01$ & $29 \_32$ & 95.0 & 91.6 & 5.8 & 0.1 & 2.1 & 36.6 \\
\hline $11 / 06 / 03$ & 29_32 & 89.9 & 90.2 & 38.1 & 4.1 & 0.8 & 11.7 \\
\hline $11 / 08 / 02$ & 29_32 & 77.9 & 90.6 & 71.0 & 27.3 & 0.1 & 1.5 \\
\hline $11 / 08 / 08$ & $29 \_32$ & 84.5 & 92.9 & 66.0 & 26.3 & 0.1 & 1.2 \\
\hline $11 / 08 / 14$ & $29 \_32$ & 87.8 & 93.2 & 77.4 & 36.0 & 0.1 & 1.4 \\
\hline $11 / 08 / 23$ & $29 \_32$ & 90.0 & 92.2 & 77.8 & 54.0 & 0.1 & 1.0 \\
\hline $11 / 08 / 29$ & 29_32 & 79.6 & 91.0 & 52.4 & 19.7 & 0.1 & 2.2 \\
\hline $11 / 10 / 01$ & 29_32 & 87.1 & 92.2 & 33.9 & 5.5 & 0.1 & 9.1 \\
\hline $11 / 12 / 03$ & 29_32 & 82.8 & 93.4 & 30.7 & 1.7 & 0.1 & 12.9 \\
\hline $11 / 08 / 29$ & 29_33 & 90.6 & 90.8 & 20.8 & 15.1 & 2.3 & 5.6 \\
\hline $11 / 08 / 30$ & 30_31 & 85.7 & 85.1 & 24.7 & 9.2 & 3.2 & 21.0 \\
\hline $11 / 08 / 30$ & 30_32 & 86.0 & 91.4 & 20.9 & 10.2 & 0.4 & 5.5 \\
\hline $11 / 08 / 30$ & 30_33 & 94.9 & 93.0 & 11.1 & 3.6 & 1.5 & 9.1 \\
\hline \multicolumn{2}{|c|}{ Average } & 87.0 & 92.0 & 39.1 & 14.3 & 1.1 & 7.9 \\
\hline
\end{tabular}

Table 6. Results for integrated-CCL thresholds of the maximum accuracy values in Fig. 11 (CLAUDIA1-CAI: 0.75, CLAUDIA3-CAI: 0.5) in the Amazon.

\begin{tabular}{|c|c|c|c|c|c|c|c|}
\hline \multirow[b]{2}{*}{$\begin{array}{l}\text { Date } \\
(\mathrm{yy} / \mathrm{mm} / \mathrm{dd})\end{array}$} & \multirow[b]{2}{*}{$\begin{array}{r}\text { Location } \\
\text { (CAI Path_Frame) }\end{array}$} & \multicolumn{2}{|c|}{ Accuracy (\%) } & \multicolumn{2}{|c|}{ Overlook (\%) } & \multicolumn{2}{|c|}{ Overestimate (\%) } \\
\hline & & $\begin{array}{r}\text { CLAUDIA1 } \\
(0.75)\end{array}$ & $\begin{array}{r}\text { CLAUDIA3 } \\
(0.5)\end{array}$ & $\begin{array}{r}\text { CLAUDIA1 } \\
(0.75)\end{array}$ & $\begin{array}{r}\text { CLAUDIA3 } \\
(0.5)\end{array}$ & $\begin{array}{r}\text { CLAUDIA1 } \\
(0.75)\end{array}$ & $\begin{array}{r}\text { CLAUDIA3 } \\
(0.5)\end{array}$ \\
\hline $11 / 08 / 28$ & 28_31 & 86.9 & 95.1 & 47.9 & 16.9 & 0.0 & 0.5 \\
\hline $11 / 08 / 28$ & 28_32 & 84.2 & 92.9 & 40.2 & 7.5 & 0.2 & 6.9 \\
\hline $11 / 08 / 28$ & 28_33 & 83.6 & 95.9 & 7.1 & 13.4 & 18.1 & 2.4 \\
\hline $11 / 08 / 29$ & $29 \_31$ & 89.6 & 93.8 & 21.8 & 9.5 & 1.2 & 3.5 \\
\hline $10 / 08 / 28$ & $29 \_32$ & 90.6 & 90.8 & 23.5 & 9.9 & 4.0 & 9.0 \\
\hline $11 / 02 / 03$ & $29 \_32$ & 88.9 & 92.9 & 27.8 & 2.4 & 1.4 & 9.9 \\
\hline $11 / 04 / 01$ & $29 \_32$ & 96.2 & 91.6 & 3.7 & 0.1 & 4.1 & 36.6 \\
\hline $11 / 06 / 03$ & $29 \_32$ & 90.9 & 90.2 & 29.3 & 4.1 & 2.4 & 11.7 \\
\hline $11 / 08 / 02$ & $29 \_32$ & 80.1 & 90.6 & 63.6 & 27.3 & 0.3 & 1.5 \\
\hline $11 / 08 / 08$ & $29 \_32$ & 85.9 & 92.9 & 59.4 & 26.3 & 0.2 & 1.2 \\
\hline $11 / 08 / 14$ & $29 \_32$ & 88.8 & 93.2 & 70.1 & 36.0 & 0.2 & 1.4 \\
\hline $11 / 08 / 23$ & $29 \_32$ & 90.9 & 92.2 & 70.3 & 54.0 & 0.1 & 1.0 \\
\hline $11 / 08 / 29$ & $29 \_32$ & 82.2 & 91.0 & 45.5 & 19.7 & 0.2 & 2.2 \\
\hline $11 / 10 / 01$ & $29 \_32$ & 89.7 & 92.2 & 26.6 & 5.5 & 0.4 & 9.1 \\
\hline $11 / 12 / 03$ & $29 \_32$ & 86.7 & 93.4 & 23.3 & 1.7 & 0.5 & 12.9 \\
\hline $11 / 08 / 29$ & 29_33 & 90.9 & 90.8 & 13.5 & 15.1 & 6.4 & 5.6 \\
\hline $11 / 08 / 30$ & 30_31 & 87.1 & 85.1 & 20.4 & 9.2 & 4.9 & 21.0 \\
\hline $11 / 08 / 30$ & 30_32 & 89.9 & 91.4 & 14.7 & 10.2 & 1.0 & 5.5 \\
\hline $11 / 08 / 30$ & 30_33 & 95.1 & 93.0 & 7.0 & 3.6 & 3.6 & 9.1 \\
\hline \multicolumn{2}{|c|}{ Average } & 88.3 & 92.0 & 32.4 & 14.3 & 2.6 & 7.9 \\
\hline
\end{tabular}


Table 7. Results for integrated-CCL thresholds of 0.33 for CLAUDIA1-CAI and 0.5 for CLAUDIA3-CAI in Borneo.

\begin{tabular}{|c|c|c|c|c|c|c|c|}
\hline \multirow[b]{2}{*}{$\begin{array}{l}\text { Date } \\
(\mathrm{yy} / \mathrm{mm} / \mathrm{dd})\end{array}$} & \multirow[b]{2}{*}{$\begin{array}{r}\text { Location } \\
\text { (CAI Path_Frame) }\end{array}$} & \multicolumn{2}{|c|}{ Accuracy $(\%)$} & \multicolumn{2}{|c|}{ Overlook (\%) } & \multicolumn{2}{|c|}{ Overestimate $(\%)$} \\
\hline & & $\begin{array}{r}\text { CLAUDIA1 } \\
(0.33)\end{array}$ & $\begin{array}{r}\text { CLAUDIA3 } \\
(0.5)\end{array}$ & $\begin{array}{r}\text { CLAUDIA1 } \\
(0.33)\end{array}$ & $\begin{array}{r}\text { CLAUDIA3 } \\
(0.5)\end{array}$ & $\begin{array}{r}\text { CLAUDIA1 } \\
(0.33)\end{array}$ & $\begin{array}{r}\text { CLAUDIA3 } \\
(0.5)\end{array}$ \\
\hline $10 / 04 / 02$ & 7_30 & 89.7 & 91.7 & 28.8 & 1.7 & 0.1 & 12.0 \\
\hline $10 / 01 / 02$ & 7_31 & 85.6 & 85.0 & 25.8 & 1.8 & 0.6 & 31.1 \\
\hline $10 / 04 / 02$ & 7_31 & 94.8 & 85.4 & 8.3 & 0.6 & 3.5 & 22.8 \\
\hline 10/07/01 & 7_31 & 90.8 & 92.2 & 29.0 & 5.0 & 0.4 & 9.0 \\
\hline 10/07/07 & 7_31 & 76.5 & 85.9 & 54.2 & 22.5 & 0.5 & 7.8 \\
\hline $10 / 07 / 13$ & 7_31 & 88.2 & 89.1 & 32.6 & 5.8 & 2.0 & 13.3 \\
\hline $10 / 07 / 19$ & 7_31 & 77.1 & 88.4 & 31.1 & 11.0 & 1.0 & 13.5 \\
\hline $10 / 07 / 28$ & 7_31 & 70.6 & 81.5 & 44.8 & 8.2 & 1.1 & 37.5 \\
\hline $10 / 09 / 02$ & 7_31 & 89.3 & 87.8 & 37.8 & 6.5 & 1.3 & 14.2 \\
\hline $10 / 11 / 01$ & 7_31 & 85.8 & 81.8 & 20.6 & 0.4 & 1.2 & 54.7 \\
\hline \multicolumn{2}{|c|}{ Average } & 84.8 & 86.9 & 31.3 & 6.3 & 1.2 & 21.6 \\
\hline
\end{tabular}

Table 8. Results for integrated-CCL thresholds of the maximum accuracy values in Fig. 13 (CLAUDIA1-CAI: 0.85, CLAUDIA3-CAI: 0.35) in Borneo.

\begin{tabular}{|c|c|c|c|c|c|c|c|}
\hline \multirow[b]{2}{*}{$\begin{array}{l}\text { Date } \\
(\mathrm{yy} / \mathrm{mm} / \mathrm{dd})\end{array}$} & \multirow[b]{2}{*}{$\begin{array}{r}\text { Location } \\
\text { (CAI Path_Frame) }\end{array}$} & \multicolumn{2}{|c|}{ Accuracy (\%) } & \multicolumn{2}{|c|}{ Overlook (\%) } & \multicolumn{2}{|c|}{ Overestimate $(\%)$} \\
\hline & & $\begin{array}{r}\text { CLAUDIA1 } \\
(0.85)\end{array}$ & $\begin{array}{r}\text { CLAUDIA3 } \\
(0.35)\end{array}$ & $\begin{array}{r}\text { CLAUDIA1 } \\
(0.85)\end{array}$ & $\begin{array}{r}\text { CLAUDIA3 } \\
(0.35)\end{array}$ & $\begin{array}{r}\text { CLAUDIA1 } \\
(0.85)\end{array}$ & $\begin{array}{r}\text { CLAUDIA3 } \\
(0.35)\end{array}$ \\
\hline $10 / 04 / 02$ & 7_30 & 91.9 & 94.6 & 22.3 & 8.5 & 0.3 & 3.8 \\
\hline $10 / 01 / 02$ & 7_31 & 89.2 & 90.7 & 16.8 & 8.0 & 3.6 & 10.9 \\
\hline $10 / 04 / 02$ & 7_31 & 93.8 & 91.5 & 4.6 & 2.3 & 7.2 & 12.2 \\
\hline 10/07/01 & 7_31 & 92.1 & 93.2 & 21.5 & 10.3 & 1.9 & 5.3 \\
\hline 10/07/07 & 7_31 & 79.4 & 83.5 & 46.1 & 33.0 & 1.6 & 4.2 \\
\hline $10 / 07 / 13$ & 7_31 & 88.9 & 90.9 & 25.1 & 11.4 & 4.4 & 7.9 \\
\hline $10 / 07 / 19$ & 7_31 & 81.7 & 83.4 & 24.1 & 20.1 & 2.7 & 7.1 \\
\hline $10 / 07 / 28$ & 7_31 & 77.3 & 80.7 & 33.2 & 18.9 & 3.2 & 20.0 \\
\hline $10 / 09 / 02$ & 7_31 & 90.3 & 90.6 & 29.0 & 12.3 & 3.0 & 8.3 \\
\hline 10/11/01 & 7_31 & 90.8 & 89.4 & 10.9 & 3.3 & 5.8 & 25.5 \\
\hline \multicolumn{2}{|c|}{ Average } & 87.5 & 88.8 & 23.4 & 12.8 & 3.4 & 10.5 \\
\hline
\end{tabular}

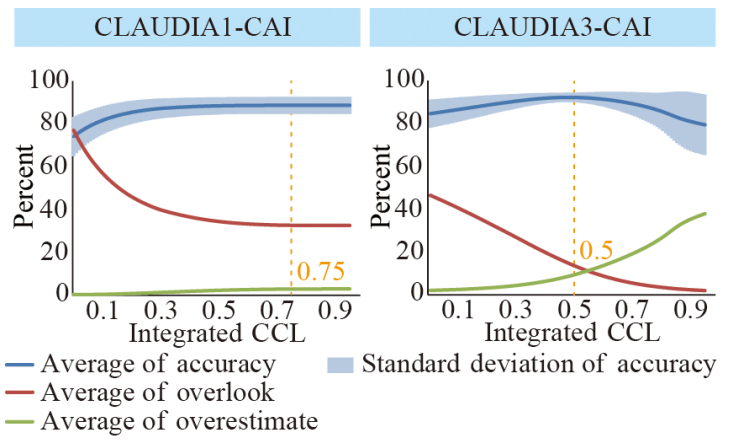

Figure 12. Average accuracy, overlook, and overestimate for all data for the Amazon. The most suitable integrated-CCL thresholds are 0.75 for CLAUDIA1-CAI and 0.5 for CLAUDIA3-CAI in the Amazon. mate. We used the CLAUDIA1-CAI result as the standard image.

In Australia and Algeria, the overlook was greater than the overestimate. This means that there was a tendency that CLAUDIA3-CAI was judged to be clear, despite CLAUDIA1-CAI being judged cloudy in Australia and Algeria. In Japan, Borneo, Canada, and Alaska, the overestimate was greater than the overlook. This means that there was tendency that CLAUDIA3-CAI was judged to be cloudy, despite CLAUIDA1-CAI being judged clear in Japan, Borneo, Canada, and Alaska. In Thailand and Mongolia, there was seasonal variation. In Thailand, the overlook was greater than the overestimate from March to May, and the overestimate was greater than the overlook from June to February. In Mongolia, the overestimate was greater than the overlook from February to March, and the overlook was greater than the overestimate from April to January. 

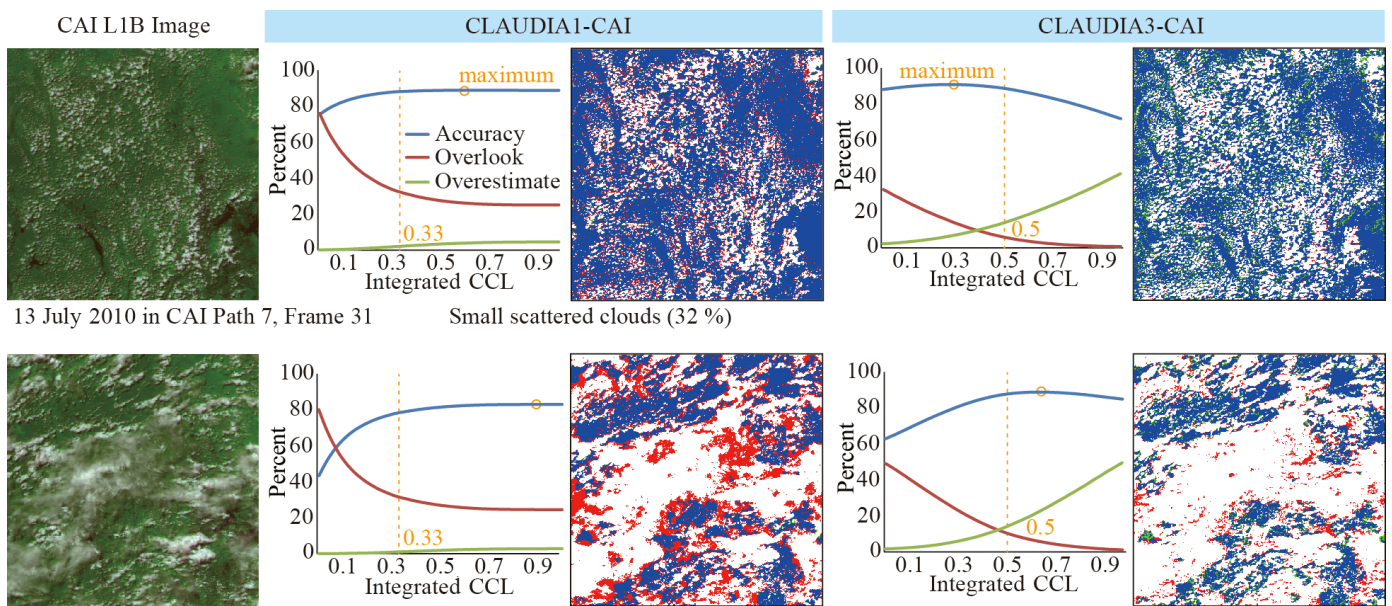

Small scattered clouds ( $32 \%$ )

19 July 2010 in CAI Path 7, Frame 31
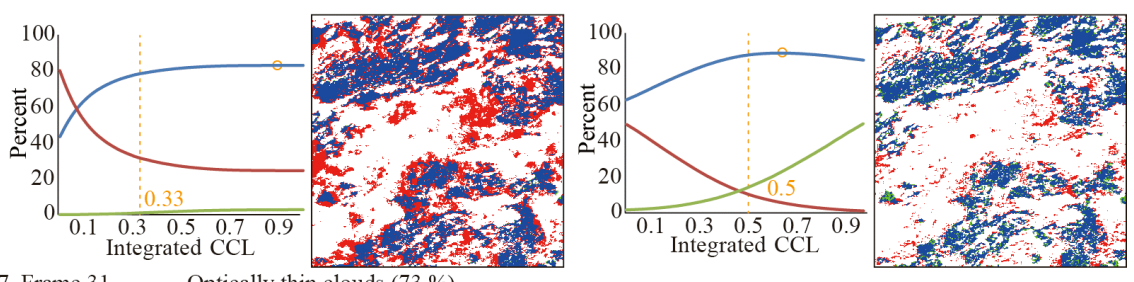

Optically thin clouds ( $73 \%)$

$\square$ Both determined cloudy Determined as cloudy despite clear

Both determined clear Determined as clear despite cloudy

Figure 13. Figure 13 compares the results of the visual inspection images and the output images for two select cases in Borneo: small scattered clouds and optically thin clouds. We used the visual inspection result as the standard image. The comparison of the results for Borneo is similar to that for the Amazon. Figure 14 shows the average accuracy, overlook, and overestimate of all data for all cases in Borneo. These results indicate that the most suitable integrated-CCL thresholds are 0.85 for the CLAUDIA1-CAI and 0.35 for CLAUDIA3CAI in Borneo. Since the curved lines of the overestimate and overlook intersect in the same way as the Amazon cases, CLAUDIA3-CAI can appropriately determine the boundary between cloudy and clear sky.
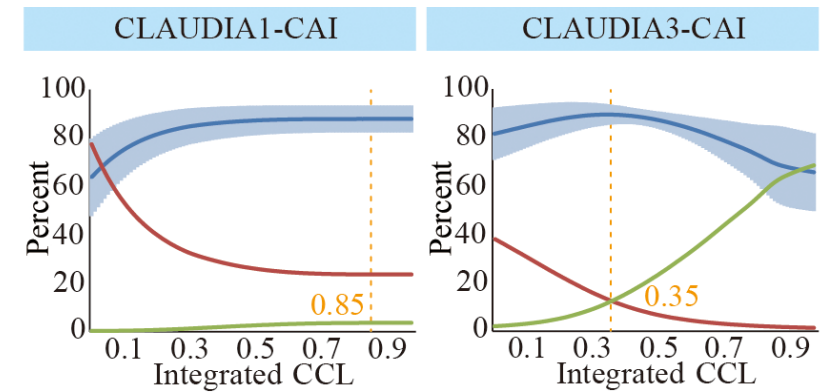

- Average of accuracy

- Average of overlook

- Average of overestimate

Figure 14. Comparison of the visual inspection images and the output images in Borneo. Orange circles indicate the maximum accuracy values. Orange dotted lines indicate the integrated-CCL thresholds. Blue line indicates the accuracy, red line indicates the overlook, and green line indicates the overestimate.

Figure 10 compares the output images of CLAUDIA1CAI and CLAUDIA3-CAI for select cases in each region.

In Australia and Algeria, CLAUDIA3-CAI could identify bright surfaces; however, there were a few oversights at the edges of clouds. In Japan, CLAUDIA3-CAI misjudged vegetation areas as clouds. In Borneo, CLAUDIA3-CAI could identify optically thin clouds. In Canada and Alaska, they were snow- or ice-covered scenes. Since the CAI is not equipped with any thermal infrared bands, cloud discrimination based on the temperature at the top of clouds is not feasible. Accordingly, it is difficult to discriminate between ice or snow and clouds. The difference or similarity between CLAUDIA1-CAI and CLAUDIA3-CAI was attributed to this source of error. In Thailand, CLAUDIA3-CAI could judge smoke as noncloud, despite CLAUDIA1-CAI misjudging smoke as cloud; however, there were oversights of optically thin clouds and the edges of clouds on 3 April 2013. Furthermore CLAUDIA3-CAI misjudged muddy rivers and boundaries between land and water as cloudy. This was also reported for CLAUDIA1-CAI in a previous study (Oishi et al., 2014). Conversely, CLAUDIA3-CAI could identify optically thin clouds on 2 September 2012. In Mongolia, there was a snow-covered scene on 3 February 2013 and the same as Canada and Alaska. On the other hand CLAUDIA3-CAI could identify bright surface; however, there were a few oversights at the edges of clouds on 2 June 2012.

\subsection{Results in the Amazon}

Figure 11 compares the visual inspection images and the output images for four select cases in the Amazon: low cloud cover, high cloud cover, small scattered clouds, and optically thin clouds. We used the visual inspection result as the standard image.

CLAUDIA3-CAI produced fewer overlooked clouds but slightly more overestimated clouds than CLAUDIA1-CAI did. CLAUDIA3-CAI misjudged muddy rivers on $23 \mathrm{Au}-$ gust 2011 in CAI Path 29, Frame 32 and around clouds on 1 April 2011 in CAI Path 29, Frame 32. The maximum accuracy values of CLAUDIA3-CAI and the CLAUDIA1-CAI 
occur at different integrated-CCL values with the thresholds for the Amazon. Figure 12 shows the average accuracy, overlook, and overestimate of all the data in the Amazon for all 19 cases. These results indicate that the most suitable integratedCCL thresholds are 0.75 for CLAUDIA1-CAI and 0.5 for CLAUDIA3-CAI in the Amazon. Since the curved lines of the overestimate and overlook intersect, CLAUDIA3-CAI can appropriately determine the boundary between cloudy and clear sky.

Table 5 shows the results for an integrated-CCL threshold of 0.33 for CLAUDIA1-CAI and 0.5 for CLAUDIA3CAI, and Table 6 shows the results for an integratedCCL threshold of the maximum accuracy values in Fig. 12 (CLAUDIA1-CAI: 0.75, CLAUDIA3-CAI: 0.5). There was no notable change in the accuracies with the season or location. When the integrated-CCL threshold was 0.33 for CLAUDIA1-CAI and 0.5 for CLAUDIA3-CAI, the accuracies were 87.0 and $92.0 \%$, respectively. When the accuracy of CLAUDIA1-CAI was higher than that of CLAUDIA3CAI, optically thick clouds covered a large area of the input images. Furthermore, when the integrated-CCL threshold was 0.75 for CLAUDIA1-CAI and 0.5 for CLAUDIA3CAI, the accuracies were at their highest, at 88.3 and $92.0 \%$, respectively. In both cases, the accuracy of CLAUDIA3-CAI was higher than that of CLAUDIA1-CAI.

\subsection{Results in Borneo}

Average accuracy, overlook, and overestimate for all data for Borneo. The most suitable integrated-CCL thresholds are 0.85 for CLAUDIA1-CAI and 0.35 for CLAUDIA3-CAI in Borneo.

Table 7 shows the results for an integrated-CCL threshold of 0.33 for CLAUDIA1-CAI and 0.5 for CLAUDIA3CAI, and Table 8 shows the results for an integratedCCL threshold of the maximum accuracy values in Fig. 14 (CLAUDIA1-CAI: 0.85, CLAUDIA3-CAI: 0.35). There was no notable change in the accuracies with the season or location, similar to the results for the Amazon. For an integrated-CCL threshold of 0.33 for CLAUDIA1-CAI and 0.5 for CLAUDIA3-CAI, the accuracies were 84.8 and $86.9 \%$, respectively. Furthermore, for an integratedCCL threshold of 0.85 for CLAUDIA1-CAI and 0.35 for CLAUDIA3-CAI, the highest accuracies of 87.5 and $88.8 \%$, respectively, were obtained. In both cases, the accuracy of CLAUDIA3-CAI was greater than that of CLAUDIA1-CAI.

\section{Discussions and conclusions}

Comparative results for CLAUDIA1-CAI and CLAUDIA3CAI for various land cover types indicated that CLAUDIA3CAI had a tendency to identify bright surface and optically thin clouds; however, CLAUDIA3-CAI had a tendency to misjudge the edges of clouds compared with CLAUDIA1-
CAI. There are tradeoffs in maximizing accuracy while minimizing overlook and overestimate. Thus, it is sufficient to change the integrated-CCL threshold according to the purpose. Furthermore, CLAUDIA3-CAI misjudged vegetation areas as clouds in Japan. It is necessary to add clear training data of Japanese vegetation areas for CLAUDIA3.

The averaged accuracy of CLAUDIA 3 used with GOSAT CAI data (CLAUDIA3-CAI) was approximately $89.5 \%$ in tropical rainforests, which was greater than that of CLAUDIA1-CAI (85.9\%) for the test cases presented here. This is mainly because, in contrast to CLAUDIA1-CAI, CLAUDIA3-CAI can detect optically thin clouds and the edges of clouds, which prevents cloud-contaminated FTS2 data from being processed as cloud-free FTS-2 data in the greenhouse gas concentration calculations. However, CLAUDIA3-CAI tends to overestimate the surroundings of clouds, which are judged to be cloudy despite being clear. Thus, CLAUDIA3-CAI is not expected to increase the amount of the FTS-2 data that can be used to estimate greenhouse gas concentrations in tropical rainforests. Conversely, CLAUDIA3-CAI may be able to detect optically thin clouds that cannot be detected by visual inspection.

CLAUDIA3-CAI misjudged muddy rivers and boundaries between land and water as cloudy in the same manner as CLAUDIA1-CAI. This has three possible causes: (1) insufficient training data on muddy rivers so the differences in the spectral reflectance properties of muddy water and other water cannot be distinguished; (2) deviation of the positions in each CAI band owing to the band-to-band registration error; and (3) insufficient resolution of the surface albedo data. The surface albedo data were generated at $1 / 8^{\circ}$ resolution by separating the land and water regions. If the border pixels between land and water regions were mixed pixels, the albedo data of $1 / 8^{\circ}$ areas that include the mixed pixels would be included. To decrease this effect, higher-resolution surface albedo data are needed. For boundaries between land and water, the resolution of surface albedo data is being investigated because it may be the main problem: the misjudged regions and grid pattern of albedo data match. CLAUDIA3-CAI is more sensitive to differences between land and water than CLAUDIA1-CAI because there is a large difference in the structure of support vectors between land and water. However, generating higher-resolution surface albedo data from CAI L1B data for 10 recurrent cycles cannot completely remove clouds in the minimum reflectance calculation. To solve this, initially we need to confirm whether $500 \mathrm{~m}$ resolution albedo data should be used. If necessary, we will develop a new method for generating surface albedo data. For example, simple cloud discrimination could be added to calculate the minimum reflectance, and if it is a cloud-contaminated pixel then the pixel is replaced by a minimum reflectance pixel, which is calculated from the same month over several years.

Although we used MODIS data as training images to generate support vectors in this study, the MODIS data and 
CAI data depend on observation conditions. In future work, we will use CAI data as training images to perform cloud discrimination for CAI data. Furthermore, we will verify CLAUDIA3-CAI by using global CAI data with an alternative method. For instance, it can be compared with satellite lidar data, such as CALIPSO, because it is impossible to perform a visual inspection of global data and visual inspection is also itself not perfect. Addressing these points will make CLAUDIA3-CAI more reliable for GOSAT-2 CAI-2 cloud discrimination.

Data availability. The raw data used in this study are available to download from GOSAT Data Archive Service (GDAS, https: //data2.gosat.nies.go.jp/index_en.html).

Author contributions. YO, HI, TYN, RN, and TM conceived and designed the studies; YO performed evaluations and analyzed the data; HI contributed analysis tools; YO wrote the paper.

Competing interests. The authors declare no conflict of interest.

Acknowledgements. This research is supported by the GOSAT-2 Project at the National Institute for Environmental Studies (NIES), Japan $(2015,2016)$ and based on results obtained as part of a project commissioned by the New Energy and Industrial Technology Development Organization (NEDO). NIES and NEDO had no role in the design of the study; in the collection, analyses, or interpretation of data; in the writing of the manuscript, or in the decision to publish the results.

The authors would like to thank the GOSAT Project, GOSAT-2 Project, and Takahiro Endo for their helpful comments; Takuya Hirose for his assistance with visual inspection. We appreciate an anonymous reviewer who gave useful comments to the previous version of the manuscript.

Edited by: Murray Hamilton

Reviewed by: Thomas E. Taylor and one anonymous referee

\section{References}

Ackerman, S., Frey, R., Strabala, K., Liu, Y., Gumley, L., Baum, B., and Menzel, P.: Discriminating clear-sky from cloud with MODIS algorithm theoretical basis document (MOD35), available at: http://modis-atmos.gsfc.nasa.gov/_docs/MOD35_ ATBD_Collection6.pdf (last access: 8 December 2017), 2010.

Baccini, A., Goetz, S. J., Walker, W. S., Laporte, N. T., Sun, M., Sulla-Menache, D., Hackler, J., Beck, P. S. A., Dubayah, R., Friedl, M. A., Samanta, S., and Houghton, R. A.: Estimated carbon dioxide emissions from tropical deforestation improved by carbon-density maps, Nat. Clim. Change, 2, 182-185, https://doi.org/10.1038/nclimate1354, 2012.

Boser, B., Guyon, I., and Vapnik, V.: A training algorithm for optimal margin classifiers, COLT '92 Proc. 5th Worksh. on Computat. Learning Theory, 144-152, https://doi.org/10.1145/130385.130401, 1992.

Cortes, C. and Vapnik, V.: Support-vector networks, Mach. Learn, 20, 273-297, https://doi.org/10.1023/A:1022627411411, 1995.

FAO: Global Forest Resources Assessment 2005, available at: http: //www.fao.org/docrep/008/a0400e/a0400e00.htm (last access: 8 December 2017), 2005.

FAO and ITTO: The state of forests in the Amazon Basin, Congo Basin and Southeast Asia, available at: www.fao.org/docrep/014/ i2247e/i2247e00.pdf (last access: 8 December 2017), 2011.

Fukuda, S., Nakajima, T., Takenaka, H., Higurashi, A., Kikuchi, N., Nakajima, T. Y., and Ishida, H.: New approaches to removing cloud shadows and evaluating the $380 \mathrm{~nm}$ surface reflectance for improved aerosol optical thickness retrievals from the GOSAT/TANSO-Cloud and Aerosol Imager, J. Geophys. Res., 118, 13520-13531, https://doi.org/10.1002/2013JD020090 2013.

Ishida, H. and Nakajima, T. Y.: Development of an unbiased cloud detection algorithm for a spaceborne multispectral imager, J. Geophys. Res., 114, D07206, https://doi.org/10.1029/2008JD010710, 2009.

Ishida, H., Nakajima, T. Y., and Kikuchi, N.: Algorithm Theoretical Basis Document for GOSAT TANSO-CAI L2 cloud flag, available at: https://data2.gosat.nies.go.jp/GosatDataArchiveService/ doc/GU/ATBD_CAIL2CLDFLAG_V1.0_en.pdf (last access: 8 December 2017), 2011a.

Ishida, H., Nakajima, T. Y., Yokota, T., Kikuchi, N., and Watanabe, H.: Investigation of GOSAT TANSO-CAI cloud screening ability through an intersatellite comparison, J. Appl. Meteorol. Climatol., 50, 1571-1586, https://doi.org/10.1175/2011JAMC2672.1, $2011 b$.

Ishida, H., Oishi, Y., Morita, K., Moriwaki, K., and Nakajima, T. Y.: Development of a support vector machine based cloud detection method for MODIS with the adjustability to various conditions, Remote Sens. Environ., 205, 390-407, https://doi.org/10.1016/j.rse.2017.11.003, 2018.

Ishihara, H. and Nobuta, K.: Algorithm Theoretical Basis Document (ATBD) on the processing of GOSAT TANSO-CAI L3 Global Reflectance Products, available at: https://data2.gosat.nies.go.jp/GosatDataArchiveService/doc/ GU/ATBD_CAIL3REF_V1.0_en.pdf (last access: 8 December 2017), 2013.

Maksyutov, S., Takagi, H., Valsala, V. K., Saito, M. Oda, T., Saeki T., Belikov, D. A., Saito, T., Ito, A., Yoshida, Y., Morino, I., Uchino, O., Andres, R. J., and Yokota, T.: Regional $\mathrm{CO}_{2}$ flux estimates for 2009-2010 based on GOSAT and groundbased $\mathrm{CO}_{2}$ observations, Atmos. Chem. Phys., 13, 9351-9373, https://doi.org/10.5194/acp-13-9351-2013, 2013.

Maksyutov, S., Takagi, H., Belikov, D. A., Saito, M., Oda, T., Saeki, T., Valsala, V. K., Saito, R., Ito, A., Yoshida, Y., Morino, I., Uchino, O., and Yokota, T.: Algorithm Theoretical Basis Document (ATBD) for the estimation of $\mathrm{CO}_{2}$ fluxes and concentration distributions from GOSAT and surface-based $\mathrm{CO}_{2}$ data, available at: https://data2.gosat.nies.go.jp/GosatDataArchiveService/ doc/GU/ATBD_L4CO2_V1.0_en.pdf (last access: 8 December 2017), 2014.

Mather, J. H. and Voyles, J. W.: The ARM Climate Research Facility: A review of structure and capabilities, B. Am. Me- 
teor. Soc., 94, 377-392, https://doi.org/10.1175/BAMS-D-11$00218.1,2013$.

Ministry of the Environment, Japan: New mechanisms information platform, Joint Crediting Mechanism (JCM), available at: https: //www.carbon-markets.go.jp/eng/jcm/index.html (last access: 8 December 2017), 2015.

NIES GOSAT-2 Project: GOSAT-2 Project at the National Institute for Environmental Studies, about GOSAT-2, available at: www. gosat-2.nies.go.jp (last access: 8 December 2017), 2014.

Oishi, Y., Kamei, A., Yokota, Y., Hiraki, K., and Matsunaga, T.: Evaluation of the accuracy of GOSAT TANSO-CAI L2 cloud flag product by visual inspection in the Amazon and of the impact of changes in the IFOV sizes of TANSO-FTS, J. Remote Sens. Soc. Jpn., 34, 153-165, https://doi.org/10.11440/rssj.34.153, 2014.

Oishi, Y., Ishida, H., Nakajima, T. Y., Nakamura, R., and Matsunaga, T.: The impact of different support vectors on GOSAT2 CAI-2 L2 cloud discrimination, Remote Sens., 9, 1236, https://doi.org/10.3390/rs9121236, 2017.
Taylor, T. E., O’Dell, C. W., O’Brien, D. M., Kikuchi, N., Yokota, T., Nakajima, T. Y., Ishida, H., Crisp, D., and Nakajima, T.: Comparison of cloud-screening methods applied to GOSAT nearinfrared spectra, IEEE T. Geophys. Res. Sci., 50, 295-309, https://doi.org/10.1109/TGRS.2011.2160270, 2012.

Uchino, O., Kikuchi, N., Sakai, T., Morino, I., Yoshida, Y., Nagai, T., Shimizu, A., Shibata, T., Yamazaki, A., Uchiyama, A., Kikuchi, N., Oshchepkov, S., Bril, A., and Yokota, T.: Influence of aerosols and thin cirrus clouds on the GOSAT-observed $\mathrm{CO}_{2}$ : a case study over Tsukuba, Atmos. Chem. Phys., 12, 3393-3404, https://doi.org/10.5194/acp-12-3393-2012, 2012.

Vapnik, V. and Lerner, A.: Pattern recognition using generalized portrait method, Automat. Rem. Contr., 24, 774-780, 1963.

Yoshida, Y., Eguchi, N., Ota, Y., Kikuchi, N., Nobuta, K., Aoki, T., and Yokota, T.: Algorithm Theoretical Basis Document (ATBD) for $\mathrm{CO}_{2}$ and $\mathrm{CH} 4$ column amounts retrieval from GOSAT TANSO-FTS SWIR, available at: https://data2.gosat.nies.go.jp/GosatDataArchiveService/doc/ GU/ATBD_FTSSWIRL2_V1.1_en.pdf (last access: 8 December 2017), 2010. 